\title{
A FORMAÇÃO DOCENTE EM GEOGRAFIA DIANTE DOS ANSEIOS DA EDUCAÇÃO INCLUSIVA NA CONTEMPORANEIDADE
}

\author{
Stela de Jesus ${ }^{1}$ \\ Fernanda Dione Sales de Souza ${ }^{2}$ \\ Glauber Barros Alves Costa ${ }^{3}$
}

\section{RESUMO}

Este artigo discute sobre a formação docente em geografia com vistas à educação inclusiva. Tal estudo realizou-se por meio da pesquisa qualitativa com a distribuição de questionários junto aos discentes do curso de Geografia da UESB, com embasamento na pesquisa bibliográfica. O resultado parcial mostra a necessidade de formação adequada para que os geógrafos da UESB tenham condições de atuar como professores na Educação Inclusiva.

Palavras-chave: Educação inclusiva. Formação docente de Geografia.

\footnotetext{
${ }^{1}$ Licenciada e Especialista em Geografia pela Universidade Estadual do Sudoeste da Bahia (UESB). Integrante do Grupo de Pesquisa Espaço, memória e representações sociais. E-mail: stelaerro@hotmail.com

${ }^{2}$ Licenciada em Geografia pela Universidade Estadual do Sudoeste da Bahia (UESB). Integrante do Grupo de Pesquisa Espaço, memória e representações sociais. E-mail: nandadione@hotmail.com

${ }^{3}$ Orientador do estudo e professor Mestre do Departamento de Geografia da UESB. Integrante do Grupo de Pesquisa Espaço, memória e representações sociais e líder do Grupo de Pesquisa em Educação e Ensino de Geografia. E-mail: glauberbarros@hotmail.com
}

\begin{tabular}{l|l|l|l|l}
\hline Revista Extensão \& Cidadania & Vitória da Conquista & v. 1, n. 2 & p. 85-104 & jul/dez. 2013 \\
\hline
\end{tabular}




\begin{abstract}
This research discusses about teacher training in geography and education for special people. This study was carried out by means of qualitative research with the distribution of questionnaires to the students from the Geography UESB. The partial result shows the need for proper training so that geographers UESB are able to act as teachers in the education for special people.
\end{abstract}

Keywords: Special Education. Geography teacher training.

\title{
Introdução
}

Diante do panorama da formação histórica social do Brasil, é compreensível que o lema da inclusão social e educacional das classes desprivilegiadas brasileiras tenha se tornado uma máxima nas discussões políticas e sociais implementadas nas instâncias acadêmicas, parlamentares, midiáticas, pelas Organizações Não Governamentais (ONGs) e órgãos de apoio às crianças e jovens em situação de risco social e aos portadores de necessidades especiais.

Ao considerar a educação como um mecanismo de promoção social, econômica, intelectual e cultural dos sujeitos excluídos socialmente, pode-se afirmar que, para os mesmos, as condições de emancipação social por meio da educação em uma nação subjugada pela exploração da força de trabalho das classes desprivilegiadas, a má distribuição das riquezas e o estigma do subdesenvolvimento, são, perceptivelmente, situações mais complexas que dificultam a inserção social de tais sujeitos.

O objetivo deste estudo é focar o papel da educação e do trabalho docente como instrumentos preponderantes no auxílio aos anseios intelectuais, cognitivos e de socialização de uma das parcelas da sociedade brasileira que mais sofrem com o estigma da exclusão - os portadores de necessidades especiais -, tendo em vista a relevância da educação para a sociedade pós-moderna e, sobretudo, para as classes desprivilegiadas. 
Os questionamentos a serem apresentados neste estudo são direcionados aos investimentos na formação docente dos graduandos de geografia da Universidade Estadual do Sudoeste da Bahia (UESB) e à implementação das discussões sobre a educação inclusiva nesta instituição. Entendendo-se que com a falta de estrutura física adequada nos ambientes educacionais e profissionalizantes, a ausência de docentes capacitados e o apoio econômico do poder estatal, certamente será muito mais difícil para os portadores de necessidades especiais concretizarem o desejo de avançar em uma carreira acadêmica ou em alguma outra realização pessoal.

Tendo em vista estas problemáticas, quais seriam as condições oferecidas pela UESB para que os sujeitos, nessa situação, possam fazer uso dos aparatos inclusivos da instituição de ensino superior para se inserirem de maneira igualitária nos círculos intelectuais e no mercado de trabalho?

Diante da conjuntura posta para abrir a compreensão dos leitores quanto ao famigerado quadro de discriminação social e educacional da sociedade brasileira, pode-se afirmar, dessa maneira, que existe uma seleção de discussões que roubam a cena nos meios de comunicação e nos âmbitos da educação superior, as quais são pautas constantes nesses âmbitos, em detrimento dos temas da inclusão social e educacional.

Tratando dessa discussão de maneira mais aprofundada no campo educacional, entende-se que é por meio da escola e da prática docente que as condições de ascensão social dos portadores de necessidades especiais podem ser ampliadas.

Para adequação das práticas didático-pedagógicas no processo de ensino e aprendizagem dos conteúdos escolares da geografia para os portadores de necessitas especiais, torna-se preponderante a implementação de propostas de capacitação docente para a atuação destes na educação especial. Para tanto, faz-se necessário preparar o corpo docente para refletir ideologicamente sobre a desigualdade social brasileira e os processos teóricos e metodológicos da educação inclusiva em sala de aula, com a finalidade de proporcionar o acesso concreto desses sujeitos à vida social. 
A Ciência Geográfica, no aspecto da inclusão educacional, anseia propor discussões e ações mais efetivas. Percebe-se a necessidade de amplo amadurecimento das discussões geográficas quanto às práticas docentes de geografia no ensino de seus conteúdos na educação inclusiva.

Notou-se que os debates acadêmicos implementados durante a formação docente dos profissionais de geografia apresentavam fragilidades quanto à maneira de se trabalhar os conteúdos da geografia escolar com discentes portadores de alguma necessidade educacional especial. Identificado esse aspecto da formação dos discentes de geografia, aponta-se, ainda, como um fator que agrava a situação exposta, a escassez da divulgação dos trabalhos de pesquisa e de financiamento de projetos que contemplem essa temática educacional e social.

Verificou-se que alguns estudos monográficos e de pósgraduação contemplam a pesquisa e a análise de alguns casos específicos de necessidades educacionais especiais, no entanto, essa discussão se mostra insuficiente em sala de aula, ocasionando o despreparo reflexivo e de formação desses graduandos.

Por meio deste diagnóstico, esse estudo encaminhou-se na perspectiva de apontar as razões desta fragilidade presente no curso de Licenciatura Plena em Geografia, da Universidade Estadual do Sudoeste da Bahia (UESB). Foram tomadas como base teórica conceitual as obras de Amaral (1998), Pan (2005), Melo e Sampaio (2007), Poker (2007), entre outros outores que se debruçam sobre a compreensão da educação inclusiva.

Metodologicamente, esse estudo foi desenvolvido por meio de discussões singulares, aplicação de questionários, leituras complementares acerca do tema tratado e observação in locus.

\section{A educação inclusiva na contemporaneidade}

É preciso desmistificar a ideia de que o aluno com necessidades educacionais especiais é um aluno com dificuldades de aprendizagem, segundo Melo e Sampaio (2007, p. 125): "Para muitos leigos no 
assunto, as necessidades educativas especiais são interpretadas como dificuldades, no entanto, mais do que falar em dificuldades é preciso buscar ver as potencialidades. É preciso enxergar o outro pela pessoa que ele é e não por rótulos".

Sobre alguns rótulos ou atribuições, Amaral (1998, p. 20) relata:

[...] Ao dizermos (ou até mesmo pensarmos) frase do tipo: "é paralítico mas tão inteligente", "é negro tem alma de branco", "é homossexual mas tão sensível"... estamos compensando aquela característica ou condição que consideramos espúria e, portanto, negando-a ao contrapô-la a um atributo desejável - o "mas" denuncia esse movimento [...].

Nem sempre as dificuldades de aprendizagem estão ligadas à deficiência. Segundo a definição do Nacional Joint Committee of Learning Disabilides (NJCLD, 1988 apud POKER, 2007, p. 171), a dificuldade de aprendizagem é:

[...] um termo geral que se refere a um grupo heterogêneo de desordens manifestadas por dificuldades significativas na aquisição e utilização da compreensão auditiva, da fala, da leitura, da escrita e do raciocínio matemático. Tais desordens, consideradas intrínsecas ao indivíduo, presumindo-se que sejam devidas a uma disfunção do sistema nervoso central, podem ocorrer durante toda a vida. Problemas na autorregulação do comportamento, na percepção social, na interação social podem existir com as Dificuldades de Aprendizagem. Apesar das DA ocorrerem com outras deficiências (por exemplo, deficiência sensorial, deficiência mental, distúrbios socioemocionais) ou com problemas extrínsecos (por exemplo, diferenças culturais, insuficiente ou inapropriada instrução, etc.), elas não são o resultado dessas condições [...].

É preciso perceber que nem sempre as dificuldades de aprendizagem estão relacionadas às deficiências, sejam elas motoras ou sensoriais. Tais deficiências podem ocorrer juntas, mas isso não é padrão. Poderá haver alunos com necessidades educacionais especiais 
em decorrência de dificuldades de locomoção por causa de algum acidente ocorrido ainda na infância, e se anteriormente ao acidente ele fazia todas as suas atividades "normais", este aluno não terá dificuldade de aprendizagem, porém ele precisará de uma escola adequada às suas necessidades físicas e do respeito mútuo dos colegas e professores.

Veremos que o uso do termo necessidades educacionais especiais refere-se ao sujeito que:

[...] apresenta algum problema de aprendizagem ao longo de sua escolarização, que exige uma atenção mais específica e maiores recursos educacionais do que os necessários para os colegas de sua idade. Aparecem, portanto, nesta definição, duas noções extremamente relacionadas: os problemas de aprendizagem e os recursos educacionais. Ao falar de problemas de aprendizagem e evitar a terminologia da deficiência, a ênfase situa-se na escola, na resposta educacional. Sem dúvida, esta nova concepção não nega que os alunos tenham problemas especificamente vinculados a seu próprio desenvolvimento. Uma criança cega ou com paralisia cerebral apresenta inicialmente algumas dificuldades que seus colegas não têm. No entanto, a ênfase consiste agora na capacidade do centro educacional oferecer uma resposta a suas demandas [...] (MARCHESI; MARTÍN, 1995, p. 11 apud POKER, 2007, p. 174).

Poker (2007, p. 174) ainda relata que o uso do termo necessidades educacionais especiais, sugerido pelo "Relatório Warnock 4 , modificou as concepções e terminologias referentes aos alunos com insucesso escolar. O Relatório sugere que a expressão necessidades educacionais especiais seja aplicada não para rotular o aluno, mas sim, para traduzir todas as exigências para seu progresso escolar [...]”.

Mais do que classificar, precisamos entender que as especificidades de cada aluno são produtos do meio, das relações sociais e de suas dificuldades ou mesmo de suas potencialidades.

Ainda segundo Marchesi e Martins (1995 apud POKER, 2007, p. 173),

\footnotetext{
${ }^{4}$ Documento publicado em 1978, resultado do trabalho coordenado por Mary Warnock, do Departamento de Educação e Ciência da Inglaterra.
} 
De uma visão de deficiência, dificuldade ou desajuste mais determinista, centrada no sujeito, começam a ser considerados também fatores ambientais como sendo causadores dos problemas de aprendizagem. Substitui-se a nomenclatura referente às categorias de deficiência ou desajuste social e educacional pela expressão necessidades educacionais especiais [...].

O termo necessidades educacionais especiais incluem muitos educandos que possuem dificuldade de aprendizagem, além de déficit físico e social. Todo aluno é único e carrega consigo uma série de experiências psíquicas, emocionais e sociais que podem ou não contribuir para a sua aprendizagem.

Como exemplo de potencialidades, Melo e Sampaio (2007, p. 127) aponta que “[...] Os alunos Superdotados também são considerados especiais, apesar de pouco se falar de sua situação na escola. [...]”.

As necessidades são especificidades ou potencialidades que cada aluno apresenta e, por isso, precisar-se-ia de uma postura, metodologia, currículo e uma série de mudanças para a garantia da educação para todos com o devido respeito às especificidades de cada indivíduo. "[...] Desse modo, não é o aluno que deve adaptar-se à escola, mas sim, esta deve tornar-se um espaço inclusivo, a fim de cumprir seu papel social e pedagógico para a educação na diversidade [...]” (PAN, 2005, p. 136).

A escola não garante somente a formação formal e profissional que o capitalismo lhe atribuíra, ela é espaço social, é nela que os alunos se encontram e interagem com a gestão, funcionários e professores, contribuindo para seu desenvolvimento cognitivo, amadurecimento, formação social e política, mas, para isso, a escola precisa ter profissionais, em seu quadro docente, que não se intimidem em mostrar e refletir sobre a realidade dos educandos, como também sobre a realidade da sociedade capitalista.

Contudo, para que estes profissionais não se intimidem com a realidade analisada, a gestão precisa permitir, apoiar e respeitar esta postura dos licenciados. A escola é também espaço social, pois ela não é formada apenas pelo que fora referido anteriormente, mas também 
pela comunidade escolar que poderá se tornar reflexo e condicionante da realidade escolar. Incluir vai além de matricular os alunos com necessidades educacionais especiais nas escolas regulares, ou seja,

\begin{abstract}
Abrir as portas para a inclusão não significa simplesmente colocar alunos nas salas de aula do ensino regular. O debate da inclusão requer aprofundamento ético e político para com as diferenças. Caso contrário pode cair na desmemória e repetirse em silenciadas práticas de exclusão [...] (PAN, 2005, p. 106).
\end{abstract}

Se assim o fizermos, estaremos praticando uma falsa inclusão, que Silva e Facion (2005, p. 182) assim ratificam: “[...] O ato de inserir o aluno com necessidades educacionais especiais no ensino regular, por si só, seria uma pseudoinclusão, o que nos soa, no mínimo, como irresponsabilidade [...]".

Apenas inseri-los na escola regular não é incluir, pois não basta matriculá-los, é preciso garantir a estes educandos possibilidades de interação, ensino-aprendizagem e acessibilidade à própria escola, porque se isto não lhes for assegurado, eles continuam excluídos, porém matriculados ou apenas inseridos na escola. E é isso que os autores, referidos no parágrafo anterior, chamam de irresponsabilidade, e acrescentam:

[...] a criança entrará na escola, na turma comum do ensino regular e ficará. Caberá à escola encontrar respostas educativas para as necessidades específicas de cada aluno, quaisquer que sejam elas. A inclusão não admite diversificação pela segregação. Tende para uma especialização do ensino para todos [...] (SILVA; FACION, 2005, p. 190).

O ensino deve ser garantido e acessível a todos com suas especificidades, e este deve ser de qualidade. Segundo Rego (1998), na sociedade urbana e industrializada, a escola possui três funções inerentes - social, política e pedagógica -, elas são relevantes ao desenvolvimento de todo ser humano e podem ser apreendidas fora da escola, mas é nela que ocorrem as relações sociais com muitas 
pessoas, com diferentes culturas, religiões, costumes e diferenças físicas, sensoriais e motoras, que corroboram para o desenvolvimento cognitivo, emocional e psicológico dos indivíduos.

Na perspectiva vygotskiana, ${ }^{5}$

[...] o desenvolvimento das funções intelectuais especificamente humanas é mediado socialmente pelos signos e pelo outro. Ao internalizar as experiências fornecidas pela cultura a criança reconstrói, no plano individual, os modos de ação realizados externamente e aprende a organizar os próprios processos mentais. O indivíduo deixa, portanto, de se basear em signos externos e começa a se apoiar em recursos internalizados (imagens, representações mentais, conceitos etc.) [...] (REGO, 1998, p. 62).

As interações são necessárias para a formação dos indivíduos e elas contribuem para a formação cognitiva e a construção de conhecimentos. Portanto, na perspectiva de Vygotsky, “[...] construir conhecimentos implica uma ação partilhada, já que é por intermédio dos outros que as relações entre sujeito e objeto de conhecimento são estabelecidas [...]" (REGO, 1998, p. 63).

Carone (1998), em relato sobre a inclusão social, conceitua igualdade e faz um levantamento histórico, mostrando, assim, suas variações em cada momento da História. Desse modo, ela propõe uma reflexão sobre a igualdade em meio às diferenças existentes, diferenças humanas, as especificidades de cada indivíduo que devem ser valorizadas e respeitadas. Para ela, igualdade não é sinônimo de homogeneidade, mas sim de heterogeneidade convivendo com igual respeito e igualdades legais.

A discussão sobre a igualdade também continua, mas agora os atores são outros: as mulheres, os índios, os negros, outras minorias etc. Os vários universos e as várias coletividades dentro da mesma sociedade têm alcançado o espaço público, formalizando as suas demandas específicas, alterando as mentalidades por meio de discursos ilustrativos, impondo um

${ }^{5}$ Nota de termo original de Lev Vygostsky. 
patamar novo para a discussão dos direitos à diferença. Depois de séculos de lutas contra a discriminação por sexo, raça, cor, religião, convicção filosófica ou política, diferenças culturais etc., as sociedade democráticas estão sendo perpassadas por questões novas de grupos minoritários que reclamam para si mesmos uma nova forma de discriminação, dita positiva. O paradoxo gerado por esses novos atores sociais, que foram, de modo geral, excluídos da hierarquia ocupacional e da cultura hegemônica, é, de fato, meramente aparencial. Buscamos não apenas o reconhecimento social de suas demandas específicas e de algumas linhas a mais dos textos constitucionais como referência aos seus direitos políticos e sociais, mas retraçar o mapa da geografia identitária do nosso século. Não lutam, é obvio, pela desigualdade, mas sim pelos contornos das diferenças. $\mathrm{O}$ que traz de volta o velho tema da igualdade, com uma nova música. [...] (CARONE, 1998, p. 172, grifos autor).

Os novos autores das discussões sobre igualdade, na referida citação, são - neste momento histórico - diversos e distintos, pois a luta se particulariza mediante as mazelas e as precárias condições que cada grupo vai encontrando em meio ao sistema vigente. Assim, os grupos sentem a necessidade de reivindicar, de exigir melhores condições de vida e, para isto, se organizam na intenção de mudança, porém as mudanças serão feitas para amenizar as situações de cada grupo ou serão adotadas medidas que aparentemente serão tomadas como mudanças benéficas ao grupo que as solicita.

Mudaram os conceitos por igualdades durante um processo histórico de diferenças, desigualdades e segregações diversas, mas a luta pela inclusão continua. Não é apenas uma luta para incluir ou inserir em salas regulares aqueles que estão excluídos sem que haja mudanças nas metodologias, nos cursos de formações para professores ou ainda nas estruturas físicas da escola.

\section{A realidade da formação docente dos geógrafos da UESB}

A prática docente tem sofrido modificações ao ser perpassada por questionamentos e debates, por meio dos quais fica latente a 
importância da formação inicial dos professores. Esta tão mencionada formação é o que dá aos educadores subsídios para uma qualificação capaz de torná-los participantes eficazes na difusão de uma educação escolar qualificada. Com base neste pressuposto é que transformações sociais poderão ser efetivadas, as quais intervirão diretamente na vida das comunidades locais e, sobretudo, uma educação inclusiva que derrube as barreiras da injustiça social e do preconceito presente na sociedade civil.

Por meio dessa postura, previamente traçada para os profissionais de educação, entende-se que há uma exigência da capacidade de articulação da realidade social que cerca os discentes, por tais educadores, de maneira que cause significativas alterações na percepção e interpretação de mundo da comunidade escolar.

A essas exigências didático-pedagógicas, inclui-se também a formação dos docentes de geografia por meio dos ideais da educação inclusiva das minorias presentes na sociedade brasileira, sobretudo, dos portadores de necessidades educacionais especiais.

As transformações socioculturais, políticas e econômicas ocorridas no século XXI remetem à necessidade do sistema educacional repensar a forma de educar e produzir conhecimento, de maneira que as instâncias, sociedade, educadores e escolas não se desvinculem, mas que sejam veementemente articuladas entre si e se complementem para que se cumpra esse objetivo.

Diante do papel historicamente delimitado às escolas, entendese sobre essa discussão que o professor também anseia por colocação mais adequada. Segundo Cavalcanti (2006,p. 18), “[...] as transformações sociais implicam em mudanças na educação e na escola, novas tarefas igualmente se apresentam para os docentes [...]", ou seja, o docente é conduzido a pensar uma nova perspectiva de formação, na qual o educador não seja apenas alguém que domina o método e as técnicas de construção de conhecimento, mas que seja, fundamentalmente, detentor de variedades de saberes e mecanismos que possibilitem a socialização destes conhecimentos nos estabelecimentos de ensino. 
Diante disso, Pontuschka et al. (2007, p. 96) afirmam:

[...] A perspectiva de trabalhar de forma investigativa pressupõe uma mudança de atitude perante o conhecimento. Significa ultrapassar a visão da prática pedagógica como simples transmissão de um conhecimento pronto e acabado que os alunos não possuem e implica outra concepção de educação, de acordo com a qual o conhecimento é visto à luz do seu processo de produção e apropriação, como produto social de contextos históricos determinados - revelando-se, portanto, algo provisório em permanente processo de construção e reconstrução [...].

Reafirmando o que foi posto por Pontuschka et al. (2007), o processo de aprendizagem deve estar em consonância com os debates a respeito das desiguais situações de produção e apropriação do espaço social e esta tarefa deve ser flexível no tocante à forma de se transmitir conteúdos e conceitos, dada a mobilidade dos sistemas sociais e econômicos ao longo da história, tanto para discentes "normais", quanto para os portadores de necessidades especiais. Esse é, portanto, o papel do educador, o qual é delimitado por meio do contexto contemporâneo.

Quanto ao geógrafo, pode-se dizer, segundo Moreira (2007), que é possível assemelhá-lho a um cineasta, pois este, na sua concepção, desenvolve um papel de observador com "ideias na cabeça e uma câmera na mão". Assim, é papel do geógrafo estabelecer um olhar geograficamente orientado.

$O$ instrumento de leitura do mundo, que para o profissional cineasta é a câmera, e que para o geógrafo é o espaço, vem a ser utilizado com o objetivo de desenvolver uma visão das transformações ocorridas no espaço ao longo do tempo.

Eis, portanto, o ponto primaz para o desenvolvimento do trabalho docente. Ter a capacidade de articular e contextualizar a realidade em sala de aula, de forma que possa envolver o corpo discente numa constante indagação: por que o visível se apresenta como tal? 
Assim, o geógrafo atenderá aos anseios da sociedade escolar, bem como, poderá incentivar a elaboração de novas propostas políticopedagógicas para as Instituições de Ensino.

É importante reconhecer, dentro desse contexto, o objeto de estudo da geografia e a concepção que norteará o estudo de tal objeto, o qual ultrapassa as informações dos limites políticos dos territórios mundiais e as nomenclaturas dos mapas políticos administrativos como os temas mais curiosos e pertinentes a essa ciência, em detrimento do poder crítico que os temas abordados por ela podem obter. Como exemplo disso, tem-se os debates sociais segundo as necessidades da população em seu tempo histórico, assim como a influência do sistema econômico capitalista e das diversidades de relações que tal organização econômica impõe às redes estabelecidas entre o global e o local, entre outros debates imprescindíveis para a formação crítica e geográfica dos sujeitos.

De acordo com Pontuschka et al. (2007, p. 264):

[...] A Geografia contemporânea tem privilegiado o saber sobre o espaço geográfico em suas diferentes escalas de análise. Enquanto disciplina escolar, deve propiciar ao aluno a leitura e a compreensão do espaço geográfico como uma construção histórico-social, fruto das relações estabelecidas entre sociedade e natureza [...].

Ao se observar a maneira como a geografia tem sido trabalhada nas escolas, percebeu-se como esses profissionais abordam de forma insuficiente as reais problemáticas dos temas geográficos. Sendo assim, o alunado tem apenas uma perspectiva do ensino dessa matéria, a de que ela é decorativa.

Cabe ao professor ser o articulador de novas opiniões sobre o mundo e seus problemas, com uma postura metodológica que dinamize a forma de ensinar geografia, instigando o aluno a ser um sujeito capaz de pensar sobre qualquer polêmica de seu tempo e realidade, de modo que proponha soluções por meio de reivindicações asseguradas na lei. 
Destaca-se a esse respeito, a importância de se estabelecer a relação adequada da geografia ao modelo que se deseja aplicar na prática de ensino em sala de aula.

Segundo Pontuschka et al. (2007, p. 97):

[...] Assim, além de dominar conteúdos é importante que o professor desenvolva a capacidade de utilizá-los como instrumentos para desvendar e compreender a realidade do mundo, dando sentido e significado a aprendizagem [...] fornece ao aluno os instrumentos para que possa construir articulada, organizada e crítica do mundo $[\ldots]$.

A relação ajustada entre teoria e prática, no que concerne àquilo que é desenvolvido geograficamente em sala de aula, depende inteiramente de uma postura investigativa que o professor de geografia assume e realiza juntamente com os estudantes, no intuito de apreender os conteúdos da disciplina, a fim de utilizá-los para uma interpretação das novas situações postas na realidade socioespacial, a qual cerca a vida dos discentes de formas diferentes e particulares, que requer a compreensão das redes mundiais, as quais são estabelecidas em diversas escalas e esferas.

A discussão apresentada, aqui, tem por anseio basilar revelar a qualidade da formação docente dos graduandos de geografia da UESB, em relação à prática didático-pedagógica ofertada aos estudantes portadores de necessidades especiais.

Tendo em vista a discussão realizada neste estudo, pode-se afirmar que não apenas o curso de geografia possui problemas quanto à discussão e prática do tema proposto, mas também outros cursos de licenciatura da UESB apresentam esses aspectos, salientados por meio da observação dos graduandos, quanto à superficialidade ou ausência do debate sobre educação inclusiva e mesmo sobre o entendimento teórico conceitual e prático da realidade dos discentes com necessidades educacionais especiais nas escolas regulares e, sobretudo, nas instituições de ensino superior. 
Frisamos que o cerne deste debate são os conhecimentos didáticos e pedagógicos ofertados na formação docente de geografia, na UESB, assim, entende-se que outros vieses de abordagens também podem ser suscitados, quando se trata do tema inclusão social e educacional nas instituições de educação superior, tais como: as condições do transporte coletivo para o atendimento dos portadores de necessidades; o mercado de trabalho; a infraestrutura urbana e o preconceito presente na sociedade cível, contudo, este estudo se deterá na análise da realidade acadêmica com base nos argumentos inflamados pelos intelectuais (quando propagados) sobre o referido tema.

Mais adiante são apresentados os resultados da pesquisa, que revelaram o diagnóstico da formação docente dos geógrafos da UESB para a educação inclusiva, além dos recursos com os quais a instituição conta para o atendimento, inserção e a circulação dos portadores de necessidades especiais nos espaços sociais da mesma.

A pesquisa empírica e os dados objetivos e subjetivos do estudo proposto revelaram que as discussões a respeito da inclusão educacional, por meio da prática docente dos profissionais de geografia, caminham com passos vagarosos. Segundo os discentes do curso, esse debate é esporadicamente tratado em sala de aula, assim como o desenvolvimento de experiências didático-pedagógicas na ministração dos conteúdos de geografia para portadores de necessidades educacionais especiais.

Gráfico 1- As discussões sobre educação inclusiva na formação dos discentes de Geografia da UESB.

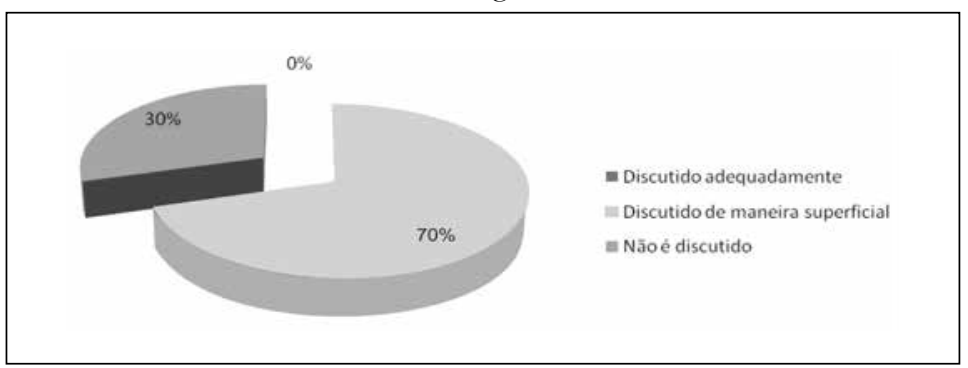

Fonte: Pesquisa de Campo, agosto de 2011. 
Sendo assim, os gráficos que serão apresentados abaixo se configuram como um espelho da amplitude que essa temática possui para o curso de geografia da UESB na atualidade. A maioria dos discentes de geografia confirmou que as problemáticas vivenciadas pelos portadores de necessidades educacionais especiais são superficialmente tratadas por meio das disciplinas da grade curricular deste curso. Em suma, atualmente, apenas a disciplina de Vivências tem trazido ao debate acadêmico a relevância do preparo docente para a inclusão educacional e social da parcela excluída dos âmbitos da educação básica e acadêmica.

Para que esse fato fosse mais palpavelmente exposto por este estudo, foi questionado aos discentes do curso se os mesmos conheciam ou já ouviram falar de algum projeto de pesquisa e extensão desenvolvido pela UESB, para discutir e proporcionar a inclusão dos portadores de necessidades especiais nessa instituição. Em relação a este questionamento, obteve-se o gráfico 2:

Gráfico 2 - A dimensão inclusiva nos projetos de pesquisa e extensão da UESB.

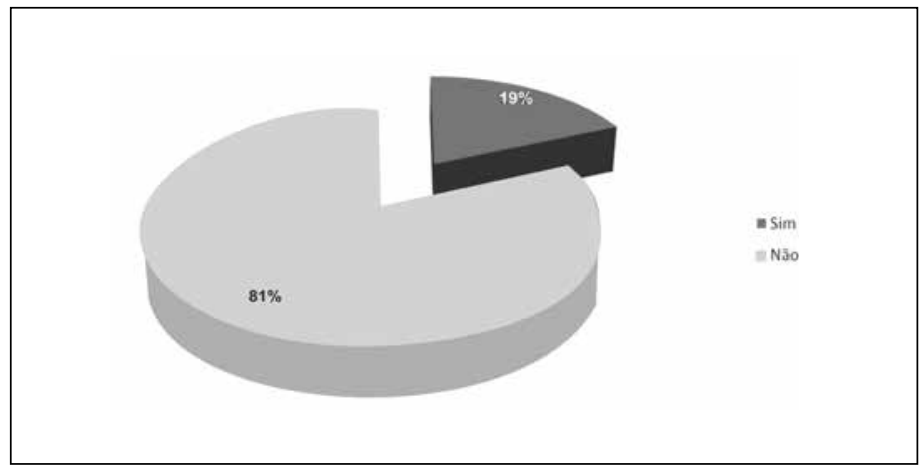

Fonte: Pesquisa de Campo, agosto de 2011.

Acerca deste questionamento, os discentes afirmaram, por meio de um percentual muito pequeno, que tinham conhecimento da existência de tais projetos. A dimensão obtida dos projetos de extensão, pesquisas e discussões sobre a educação inclusiva, nesta instituição, apenas demonstra o que já vem sendo percebido por meio de uma observação vaga das 
condições do desenvolvimento das habilidades didático-pedagógicas e metodológicas dos futuros docentes de geografia.

Diante da constatação das dificuldades encontradas na formação dos graduandos de geografia da UESB, pertinentes, sobretudo, às peculiaridades da educação inclusiva, é interessante revelar nesse estudo a postura adotada por tais discentes diante da presença de um portador de necessidade especial em sala de aula. Observam-se os resultados no gráfico abaixo:

Gráfico 3 - A perspectiva de uma educação inclusiva por meio do ensino de Geografia.

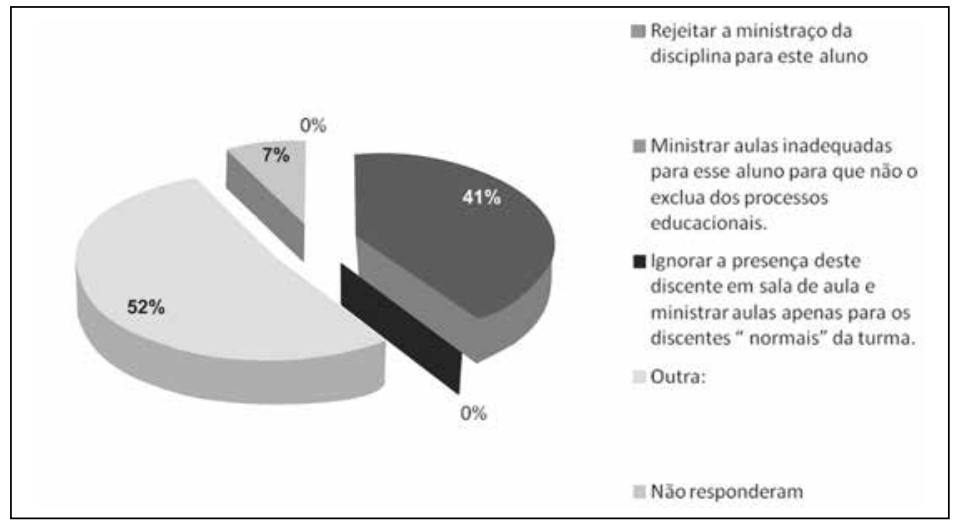

Fonte: Pesquisa de Campo, agosto de 2011.

Ao perceber o despreparo na prática didático-pedagógica no ensino de geografia aos portadores de deficiências especiais, os graduandos de geografia afirmam que é necessário adequar o ensino dos conteúdos geográficos às problemáticas presentes em sala de aula, contudo, os mesmos não conseguem sistematizar quais práticas são mais adequadas no processo de ensino e aprendizagem dos discentes com necessidades educacionais especiais.

Diante dessa afirmativa, os entrevistados apenas se posicionaram por meio de narrativas que apresentam o discurso da percepção da necessidade de adequar a prática pedagógica aos anseios da educação inclusiva ou foram francos em demonstrar que ministrarão aulas 
inadequadas para não serem os responsáveis pela evasão escolar de tais discentes.

Os dados revelaram, ainda, quanto às soluções vislumbradas pelos graduandos de geografia para possíveis alterações na formação docente do curso de geografia, que são sugestões constantes dos mesmos a solicitação de disciplinas, experiências docentes por meio de estágios, leituras e discussões a respeito do tema, de maneira que promova o amadurecimento ideológico e profissional destes docentes em formação acadêmica.

Contudo, ao serem questionados sobre a possibilidade de realização do processo de ensino e aprendizagem nas instituições de ensino regulares de maneira que se atendam adequadamente aos anseios educacionais dos portadores de necessidades especiais, os graduandos de geografia acreditam ser possível a inclusão educacional por meio do trabalho de mediação do saber desenvolvido pelos docentes, para que se obtenha, na contemporaneidade, uma escola preparada para o atendimento dos sujeitos que anseiam por qualidade de vida e inserção social mediante os processos educacionais e o desenvolvimento intelectual e cognitivo.

Eis o gráfico:

\section{Gráfico 4 - A possibilidade de realização do ensino de Geografia por meio da educação inclusiva}

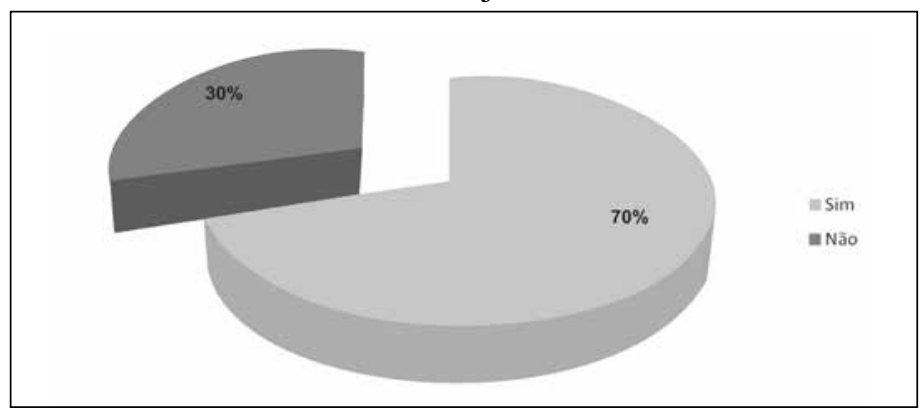

Fonte: Pesquisa de Campo, agosto de 2011. 
Sendo assim, perceptivelmente, o maior problema da inclusão educacional se restringe basicamente ao melhoramento da formação docente e às condições de trânsito e acessibilidade dos portadores de necessidades especiais nas instituições de educação.

Outro entrave existente no tocante a essa temática, está presente no âmbito do pensamento, no que tange, sobretudo, às ações preconceituosas da sociedade civil para com os portadores de deficiências. Essa, por sua vez, requer atitudes mais complexas que sufoquem tais comportamentos, e mais, que tragam alterações significativas para os mesmos.

\section{Considerações}

A educação sempre fará parte de nossas relações sociais. Na condição de seres sociais dependemos de processos sociais para interagirmos uns com os outros e com o meio e progredirmos. Embora ela se transforme e tome rumos distintos, é necessária em qualquer sociedade.

Fazer com que a educação seja base de transformação dos indivíduos pela compreensão e participação destes na realidade, como seres transformadores da condição de vida em que se encontram, significa atribuir-lhes funções sociais, políticas e psíquicas que a educação em si mesma possui, mas que, por vezes, ficam esquecidas ou não são postas em práticas por um motivo ou outro.

\section{Referências}

AMARAL, Lígia Assumpção. Sobre crocodilos e avestruzes: falando de diferenças físicas, preconceitos e sua superação. In: AQUINO, Julio Groppa. Diferenças e preconceito na escola: alternativas teóricas e práticas. São Paulo: Summus, 1998.

CARONE, Iray. Igualdade versus diferença: um tema do século. In: AQUINO, Julio Groppa (Org.). Diferenças e preconceito na escola: alternativas teóricas e práticas. São Paulo: Summus, 1998.

CAVALCANTI, Lana. Formação de professores: Concepções e práticas em Geografia. Goiânia: Vieira, 2006. 
LIBÂNEO, José Carlos. Adeusprofessor, adeus professora? Novas exigências educativas e profissão docente. 6. ed. São Paulo: Cortez, 2002.

MELO, Adriany de Ávila; SAMPAIO, Antônio Carlos Freire. Educação inclusiva e a formação de professores de Geografia: primeiras notas. Caminhos de Geografia, Uberlândia: UFU, v. 8, n. 24, p. 124-130, 2007.

MELO, Sandra Cordeiro de; LIRA, Solange Maria de; FACION, José Raimundo. Exclusão: uma metacategoria nos estudos sobre educação. In: FACION, José Raimundo. Inclusão escolar e suas implicaşões. Curitiba: IBPEX, 2005.

MOREIRA, Ruy. Pensar e Ser Geografia. São Paulo: Editora Contexto, 2007.

ORGANIZAÇÃO DAS NAÇÕES UNIDAS (ONU). Declaração Universal dos Direitos Humanos. Publicado em 1948. Disponível em: $<$ http//:portal.mj.gov.br >. Acesso em: 18 abr. 2011.

PAN, Miriam Aparecida Graciano de Souza. A deficiência mental e a educação contemporânea: uma análise dos sentidos da inclusão escolar. In: FACION, José Raimundo. Inclusão escolar e suas implicações. Curitiba: IBPEX, 2005.

POKER, Rosimar Bortolini. Dificuldades de aprendizagem e educação inclusiva. Aprender-Caderno de Filosofia e Psicologia da Educação, Vitória da Conquista: Edições UESB, ano 5, n. 9, p. 169-180, 2007.

PONTUSCHKA, Nídia Nacib; PAGANELLI, Tomoko Lyda; CACETE, Nuria Hanglei. Para ensinar e aprender geografia. São Paulo: Cortez, 2007.

REGO, Tereza Cristina R. Educação, cultura e desenvolvimento: o que pensam os professores sobre as diferenças individuais. In: AQUINO, Julio Groppa. Diferenças e preconceito na escola: alternativas teóricas e práticas. São Paulo: Summus, 1998.

SILVA, Maria de Fátima M. Caldeira; FACION, José Raimundo. Perspectivas da inclusão escolar e sua efetivação. In: FACION, José Raimundo. Inclusão escolar e suas implicações. Curitiba: IBPEX, 2005. 